\title{
Transcriptional co-activator PGC-1 $\alpha$ gene is associated with chicken skeletal muscle fiber types
}

\author{
J.T. Shu, W.J. Xu, M. Zhang, W.T. Song, Y.J. Shan, C. Song, W.Q. Zhu, \\ X.Y. Zhang and H.F. Li \\ Institute of Poultry Science, Chinese Academy of Agricultural Sciences, \\ Yangzhou, Jiangsu, China \\ Corresponding author: H.F. Li \\ E-mail: lhfxf_002@yahoo.com.cn / shujingting@163.com
}

Genet. Mol. Res. 13 (1): 895-905 (2014)

Received December 6, 2012

Accepted May 16, 2013

Published February 14, 2014

DOI http://dx.doi.org/10.4238/2014.February.14.19

\begin{abstract}
The peroxisome proliferators-activated receptor- $\gamma$ coactivator-1 $\alpha(\mathrm{PGC}-1 \alpha)$ is a candidate gene for meat quality traits because of its prominent role in muscle fiber type switching and determination. We investigated the effects of the PGC- $1 \alpha$ gene on chicken skeletal muscle fiber type switching and on other meat quality traits. Single nucleotide polymorphisms were detected by PCRSSCP and DNA sequencing, and then genotyping was performed by PCR-ligation detection reaction methods. Skeletal muscle fiber types, intramuscular fat content, shear forces, and water loss rate of the gastrocnemius lateralis muscle were measured in Qingyuan Partridge chickens and Recessive White chickens. Four SNPs, C171T in exon2, C384T in exon3, G646A in exon5, and A948G in exon8 were detected. Marker-trait association analysis indicated that G646A polymorphism was associated with skeletal myofiber type and that H1 (CCAA) was the most advantageous haplotype for skeletal myofiber
\end{abstract}


type. We concluded that polymorphisms of the PGC-1 $\alpha$ gene and their haplotypes are associated with chicken skeletal myofiber type traits.

Key words: PGC-1 $\alpha$ gene; Ligase detection reaction; Polymorphism; Myofiber type; Chicken; SNPs

\section{INTRODUCTION}

As living conditions have improved, the needs not only for meat production but for meat quality have also increased, especially in some developing countries. In animal breeding, meat quality is a complex trait, referring to the compositional, visual, and sensory traits of a carcass, or its retail cuts. The edible quality of chicken meat is stressed by Chinese consumers, which refers to the sensory attributes of cooked products, i.e., tenderness, flavor, juiciness, and color (Jiang and Groen, 2000). It has been well documented that myofiber type composition can profoundly influence postnatal muscle growth and meat quality (Karlsson et al., 1999; Pette and Staron, 2001; Yuan et al., 2010).

Skeletal muscles of vertebrates contain myofibers that differ in contractile function, mitochondrial content and metabolic properties (Berchtold et al., 2000). Slow-twitch myofibers (SM, type I) are the smallest, oxidative fibers with red color, high lipid content and many mitochondria, whereas white fast-twitch fibers (FWM, type IIb) are the largest glycolytic fibers possessing high glycogen content and few mitochondria. Red fast-twitch myofibers (FRM, type IIa) are intermediate oxidative-glycolytic fibers that are similar to SM in color but resemble FWM in their contractile property, possessing both aerobic and anaerobic metabolic capabilities. These different myofiber types also synthesize distinct arrays of contractile proteins, enzymes involved in intermediary metabolism, and regulatory proteins that act together to maintain a specific fiber phenotype (Booth and Thomason, 1991; Berchtold et al., 2000).

Studies of pathways downstream of neural activity have implicated calcium signaling through calcineurin, a calcium-calmodulin $(\mathrm{CaM})$-dependent protein phosphatase, and $\mathrm{CaM}$ kinase in the control of type-I-fiber-specific contractile proteins (Dutka et al., 2011; Hollingworth et al., 2012). However, the nuclear targets ultimately responsible for the marked and stable changes in gene expression and biological function are not well understood.

The peroxisome proliferator-activated receptor-gamma coactivator-1 $\alpha$ (PGC-1 $\alpha$ ), which was originally identified through its functional interaction with peroxisome proliferator-activated receptor-gamma, is an important regulator of many metabolic pathways, including adaptive thermogenesis, fatty acid $\beta$-oxidation, adipocyte differentiation, hepatic gluconeogenesis, muscle fiber specialization, and glucose uptake (Puigserver et al., 1998; Wu et al., 1999; Vega et al., 2000; Michael et al., 2001; Lin et al., 2002; Walter and Seebacher, 2007). Recent work has implicated PGC-1 $\alpha$ as a principal factor regulating muscle fiber type determination (Lin et al., 2002).

Qingyuan partridge chicken is an important indigenous breed distributing in Qingyuan, Guangdong Province, China. It is a light-body type breed with good meat quality, which is famous for its three "yellow", two "thin", and one "partridge" morphology features, i.e., yellow beak, shanks and skin, thin head and bone, and partridge feathers. However, there are few studies investigating the polymorphisms of candidate genes related to myofiber type in poultry. 
In the present study, we describe a new, sensitive assay for the detection of PGC-1 $\alpha$ gene based on polymerase chain reaction-ligase detection reaction (PCR-LDR). LDR was originally developed for discriminating single-base mutations or polymorphisms (Barany and Gelfand, 1991). It utilizes the ability of DNA ligase to preferentially seal adjacent oligonucleotides hybridized to target DNA in which there is perfect complementation at the nick junction. The objectives of the present study were to identify polymorphisms of the PGC-1 $\alpha$ gene, to develop a PCR-LDR method for genotyping, and to evaluate the associations of the polymorphism of this gene with myofiber type and other meat quality traits in Qingyuan partridge chicken and Recessive White chicken.

\section{MATERIAL AND METHODS}

\section{Experimental animals}

All animal studies were conducted in accordance with an animal use protocol approved by the animal use committee of the Chinese Ministry of Agriculture.

Recessive White chicken (RW, Jiang-13 strain of white Plymouth Rock) and preserved population of Qingyuan partridge chicken (QY) were used in this study. All breeds were reared with the same energy $(12.97 \mathrm{MJ} / \mathrm{kg}$ ) and protein (17.01\%) levels of diet under the same management system from the National Gene Pool for Indigenous Chicken Breeds (Yangzhou, China). All birds were kept in a stacked cage raising system with one cage for each bird. Two hundred female chickens were randomly selected from each breed using a random sampling method. Two sides of the leg gastrocnemius lateralis were collected from each individual after slaughter at the age of 16 weeks; one was for measuring IMF content, shear forces and water loss rate, and another was taken for measuring the muscle fiber diameter, muscle fiber density and densities of SM, FRM, and FWM with myosin ATPase staining. Meanwhile, $0.4 \mathrm{~mL}$ blood was collected from the ulnar vein of each individual with heparin as an anticoagulant.

\section{Histochemical analysis}

Myosin ATPase staining was used to identify myofiber type and to measure myofiber size. Briefly, muscle blocks were excised perpendicular to the direction of the myofibers. Freshly excised muscles were mounted on corks coated with gum tragacanth, rapidly frozen in liquid $\mathrm{N}$, and then stored at $-80^{\circ} \mathrm{C}$. Serial tissue sections of $10 \mathrm{~mm}$ thickness were prepared with a cryostat at $-80^{\circ} \mathrm{C}$. Sections were washed twice for $1 \mathrm{~min}$ each with $18 \mathrm{mM} \mathrm{CaCl}_{2}$ and $100 \mathrm{mM}$ Tris- $\mathrm{HCl}(\mathrm{pH}$ 7.3; pre-rinse solution) and pre-incubated for $5 \mathrm{~min}$ at $\mathrm{pH} 10.4$ (100 $\mathrm{mM}$ glycine, $1 \% \mathrm{CaCl}_{2}, 3.7 \%$ formaldehyde) at room temperature. The sections were then washed twice for $30 \mathrm{~s}$ each time with pre-rinse solution prior to incubation in $18 \mathrm{mM} \mathrm{CaCl}_{2}$, $20 \mathrm{mM}$ glycine, and $0.025 \mathrm{mM} \mathrm{ATP}, \mathrm{pH} 9.4$, for $1 \mathrm{~h} 45 \mathrm{~min}$ at $37^{\circ} \mathrm{C}$. Afterwards, sections were washed four times in $1 \% \mathrm{CaCl}_{2}$ wash solution and then rinsed in $2 \% \mathrm{CoCl}_{2}$ for $4 \mathrm{~min}$ at room temperature. Subsequently, sections were washed in distilled water four times for $20 \mathrm{~s}$ each and then stained in a $1 \%$ azure stain for $30 \mathrm{~s}$. The stained sections were finally rinsed continuously under tap water for $10 \mathrm{~min}$ and washed in distilled water for $5 \mathrm{~min}$, then dehydrated in ascending series of ethanol concentrations, delipidated in a solution of xylene - absolute ethanol (1:1, v/v) and coverslipped. Six to seven fascicles (containing about 400-500 myofibers) 
were randomly selected from five serial sections of each sample using a light microscope (Olympus BH-2, Tokyo, Japan) with camera (JVC, Yokohama, Japan) at 200X magnification, and the mean percentages of SM, FRM, and FWM myofibers were calculated using image processing software (Image-Pro Plus 4.5, Silver Spring, MD, USA). The fiber type was determined as described by Wegner et al. (2000). FWM are stained dark blue, and FRM are stained light blue, whereas SM are nonstained (Hoogenraad et al., 1979).

\section{SNP analysis and PCR amplification}

DNA was isolated from whole blood using the Purgene DNA Isolation kit (Gentra Systems, Inc., Minneapolis, MN, USA). Seventeen pairs of PCR primers (data not shown) were designed from chicken genomic and cDNA sequences to amplify the coding region of the PGC-1 $\alpha$ gene. Mutations were detected by PCR-SSCP using pooled DNA in the two chicken breeds. SNPs in genomic DNA were detected by direct gene sequencing, according to the PCR-SSCP result.

PCR was then carried out in a $20-\mu \mathrm{L}$ volume containing $1 \mu \mathrm{L}$ genomic DNA, $0.4 \mu \mathrm{L}$ primer mixture, $2 \mu \mathrm{L}$ dNTP, $0.6 \mu \mathrm{L} \mathrm{Mg}^{2+}, 2 \mu \mathrm{L}$ buffer, $4 \mu \mathrm{L}$ Q-Solution and $0.2 \mu \mathrm{L}$ Taq DNA polymerase. The amplification protocol comprised an initial denaturation and enzyme activation phase at $95^{\circ} \mathrm{C}$ for $15 \mathrm{~min}$, followed by 35 cycles of denaturation at $94^{\circ} \mathrm{C}$ for $30 \mathrm{~s}$, annealing at $56^{\circ} \mathrm{C}$ for $1 \mathrm{~min}$, and extension at $72^{\circ} \mathrm{C}$ for $1 \mathrm{~min}$, and then a final extension at $72^{\circ} \mathrm{C}$ for $7 \mathrm{~min}$. PCR products were checked on 3\% agarose gels stained with ethidium bromide to ensure the amount added in LDR.

\section{Ligase detection reaction}

According to the result of SNP scanning, four SNPs were detected in the coding region of PGC-1 $\alpha$ gene. For each SNP, three probes were designed, one common probe and two discriminating probes for the two types (Table 1). The common probe anneals to the PCR amplified template immediately downstream of the nucleotide in question. The common probes contained a phosphate in the $5^{\prime}$ terminal position and a 6-carboxyfluorescein (FAM) fluorophore at its $3^{\prime}$ end. One allelic probe has at its $3^{\prime}$ end the nucleotide corresponding to the wild-type allele. The other has at its $3^{\prime}$ end the nucleotide corresponding to the variant allele. These two allelic probes compete to anneal to the template adjacent to the common probe. This generates a double stranded region containing a nick (missing phosphodiester bond) at the nucleotide position to be tested. Only the allelic probe with perfect complementation to the template will be ligated to the common probe by the DNA ligase.

LDR reactions were carried out in a $10-\mu \mathrm{L}$ mixture containing $1 \mu \mathrm{L}$ buffer, $1 \mu \mathrm{L}$ probe mix, $0.05 \mu \mathrm{L}$ Taq DNA ligase (New England Biolabs, USA), $1 \mu \mathrm{L}$ PCR product and $6.95 \mu \mathrm{L}$ deionized water. The reaction program was as follows: an initial heating at $94^{\circ} \mathrm{C}$ for $2 \mathrm{~min}$, followed by 35 cycles of $30 \mathrm{~s}$ at $94^{\circ} \mathrm{C}$ and $2 \mathrm{~min}$ at $60^{\circ} \mathrm{C}$.

Reactions were stopped by chilling the tubes in an ethanol-dry ice bath and adding $0.5 \mathrm{~mL} 0.5 \mathrm{mM}$ EDTA. Aliquots of $1 \mu \mathrm{L}$ reaction products were mixed with $1 \mu \mathrm{L}$ loading buffer ( $83 \%$ formamide, $8.3 \mathrm{mM}$ EDTA, and $0.17 \%$ Blue Dextran) and $1 \mu \mathrm{L}$ ABI GS-500 Rox-Fluorescent molecular weight marker, denatured at $95^{\circ} \mathrm{C}$ for $2 \mathrm{~min}$., chilled rapidly on ice prior to loading on an $5 \mathrm{M}$ urea-5\% polyacrylamide gel, and electrophoresed on an ABI 3100 DNA sequencer at $3000 \mathrm{~V}$. Fluorescent ligation products were analyzed and quantified using the ABI Gene Scan 672 software. 


\begin{tabular}{|c|c|}
\hline Probe name & Probe sequences $\left(5^{\prime}-3^{\prime}\right)$ \\
\hline Exon 2 modify & P-CAACCCTGTGTCAGCCCCTCAGCTGTTTTTTTTTTTTTTTTTTTT-FAM \\
\hline Exon 2-C & тTTTTTTTTTTTTTTTTTTTCACTGAGCCAAGTGCTGGGGACACG \\
\hline Exon 2-T & TTTTTTTTTTTTTTTTTTTTTTCACTGAGCCAAGTGCTGGGGACACA \\
\hline Exon 3_modify & P-CTGTACCACTTGAGCCCCCCCAGGATTTTTTTTTTTTTTTTTTTTTTTT-FAM \\
\hline Exon $3-\mathrm{C}$ & ТTTTTTTTTTTTTTTTTTTTTTTTGCTGGAGATGACCTCAGACTGGTCG \\
\hline Exon 3-T & TTTTTTTTTTTTTTTTTTTTTTTTTTGCTGGAGATGACCTCAGACTGGTCA \\
\hline Exon 5_modify & P-TCGGGCATCGGGGAAGGGCTGGCGTTTTTTTTTTTTTTTTTTTTTTTTTTT-FAM \\
\hline Exon 5_G & тTTтTTтTтTтTTTTTTTTTTTTTTTTGCCTCCTGGGGCGGAGGGGTGCCG \\
\hline Exon 5_A & 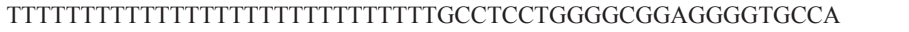 \\
\hline Exon 8 modify & P-GTTCGTAGTCAGATATTTGAGAAGTTTTTTTTTTTTTTTTTTTTTTTTTTTTT-FAM \\
\hline Exon 8_A & тTTTTTTTTTTTTTTTTTTTTTTTTTTTCTGGTTTGGTCTGAGGAGGGTCATC \\
\hline Exon 8_G & тTTTTTTTтTTTTTTTTTTTTTTTTTTTTTCTGGTTTGGTCTGAGGAGGGTCATT \\
\hline
\end{tabular}

\section{Sequencing}

To confirm the accuracy of PCR-LDR genotyping method, direct DNA sequencing of randomly selected PCR products was performed. The proportion of the sequencing samples were about $5 \%$. The results of the PCR-LDR genotyping showed $100 \%$ concordance with direct DNA sequencing of the randomly selected PCR products.

\section{Statistical analyses}

Haplotypes were inferred by the PHASE 2.0 program (Stephens et al., 2001). Association analysis of single polymorphisms or haplotypes with meat quality were determined by ANOVA using general linear model (GLM) and type III sums of squares performed by the SAS 9.0 software. The model is $Y_{\mathrm{ij}}=\mu+\mathrm{B}_{\mathrm{i}}+\mathrm{G}_{\mathrm{j}}+\mathrm{e}_{\mathrm{ij}}$, where $Y_{\mathrm{ij}}$ is an observation on the traits, $\mu$ is the overall population mean, $B_{\mathrm{i}}$ is the effect of breed, $G_{\mathrm{j}}$ is the effect of genotype or haplotype and the $e_{\mathrm{ij}}$ is the residual error. The minimum diplotype frequency was set at $2 \%$. All values are presented as least square means \pm standard error (SE).

\section{RESULTS}

\section{Characteristics of the study population}

Two hundred Recessive White chickens (RW) and 200 Qingyuan partridge chickens were enrolled in this study. The meat quality characteristics of these two breeds are summarized in Table 2. All meat quality traits except for water loss rate were significantly different between Recessive White chickens and Qingyuan partridge chickens $(\mathrm{P}<0.05)$. Qingyuan partridge chickens had a significantly higher slow-twitch myofiber ratio and significantly lower white fast-twitch myofiber ratio than did Recessive White chickens, which corroborated the sensory test results reported earlier (Chen et al., 2000). The breed with better meat quality had a higher slow-twitch myofiber ratio, which also supported the notion that myofiber types play a major role in meat quality traits.

\section{SNP screen results}

Among the 17 fragments amplified by 17 primer pairs, four fragments exhibited poly- 
morphisms. Sequence analysis revealed a $\mathrm{C} / \mathrm{T}$ substitution at position 171 in exon 2, a C/T substitution at position 384 in exon 3, a G/A point mutation at position 646 in exon 5 and an $\mathrm{A} / \mathrm{G}$ point mutation at position 948 in exon 8 of the open reading frame of the chicken PGC-1 $\alpha$ gene. However, only the G646A mutation in exon 5 caused the alteration of the corresponding amino acid from Asp to Asn, while the other three mutations were all silent mutations.

Table 2. Myofibre types and other meat quality indexes in lateral gastrocnemius in the two chicken breeds.

\begin{tabular}{lcccccc}
\hline Breeds $^{1}(\mathrm{~N})$ & $\begin{array}{c}\text { Slow-twitch } \\
\text { myofiber ratio } \\
(\%)\end{array}$ & $\begin{array}{c}\text { Red fast-twitch } \\
\text { myofiber ratio } \\
(\%)\end{array}$ & $\begin{array}{c}\text { White fast-twitch } \\
\text { myofiber ratio } \\
(\%)\end{array}$ & Shear forces (kg) & Water loss rate (\%) & IMF (\%) \\
\hline RW (200) & $38.86 \pm 4.15^{\mathrm{a}}$ & $20.55 \pm 3.12^{\mathrm{a}}$ & $51.99 \pm 3.98^{\mathrm{a}}$ & $2.606 \pm 0.075^{\mathrm{a}}$ & $31.9 \pm 0.008$ & $1.253 \pm 0.086^{\mathrm{a}}$ \\
QY (200) & $55.52 \pm 7.43^{\mathrm{b}}$ & $10.97 \pm 3.6^{\mathrm{b}}$ & $33.51 \pm 4.35^{\mathrm{b}}$ & $2.341 \pm 0.093^{\mathrm{b}}$ & $31.8 \pm 0.009$ & $1.174 \pm 0.112^{\mathrm{b}}$ \\
\hline
\end{tabular}

${ }^{\mathrm{a}, \mathrm{b}}$ Means with the different superscripts within the same column differs significantly $(\mathrm{P}<0.05) .{ }^{1} \mathrm{RW}$ and QY represent Recessive White chicken breeds and Qingyuan partridge chicken, respectively.

\section{Genotypic and allelic frequencies}

The electrophoretic profile of PCR-LDR analysis of C171T, C384T, G646A, and A948G sites are shown in Figures 1 to 4. Three genotypes (GG, GA, and AA) were found at the G646A site, while at the other three sites only two genotypes (one homozygote and one heterozygote) were found. The genotypic and allelic frequencies of the four polymorphisms in the two chicken breeds are listed in Table 3. The frequencies of the C171 and C384 alleles were 1.0 in Recessive White chickens.

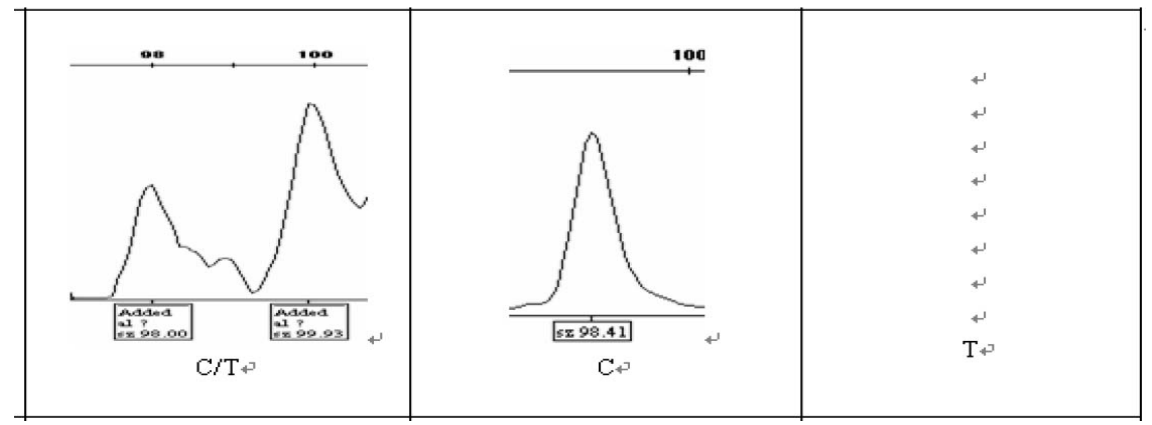

Figure 1. Genotype result of PGC-1 $\alpha$ C171T. sz $=$ size.

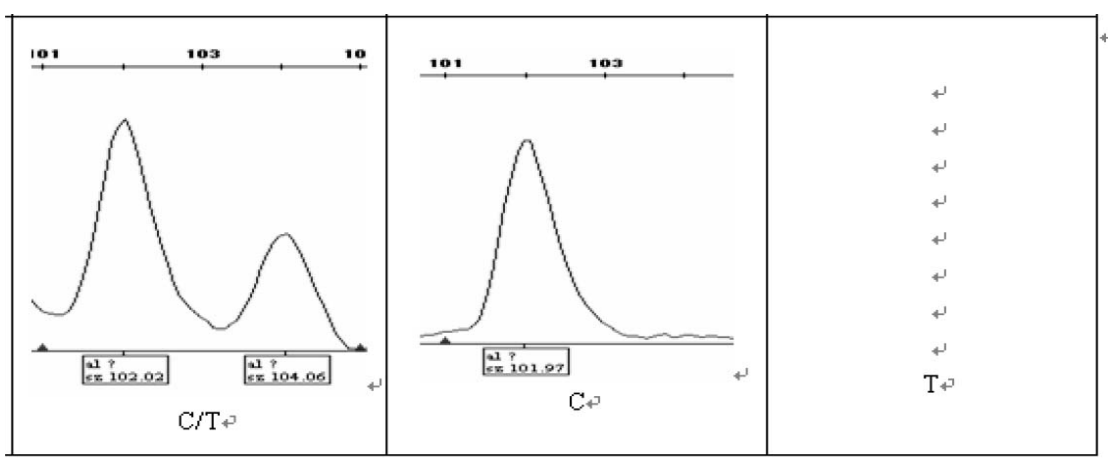

Figure 2. Genotype result of PGC-1 $\alpha$ C384T. sz $=$ size. 


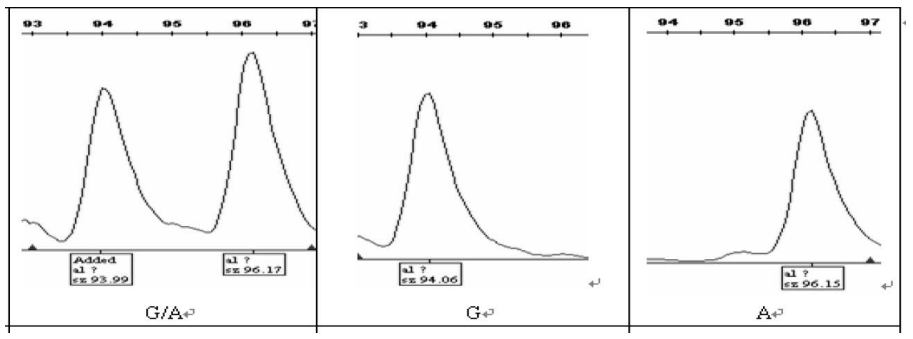

Figure 3. Genotype result of PGC-1 $1 \alpha$ G646A. sz = represents size.

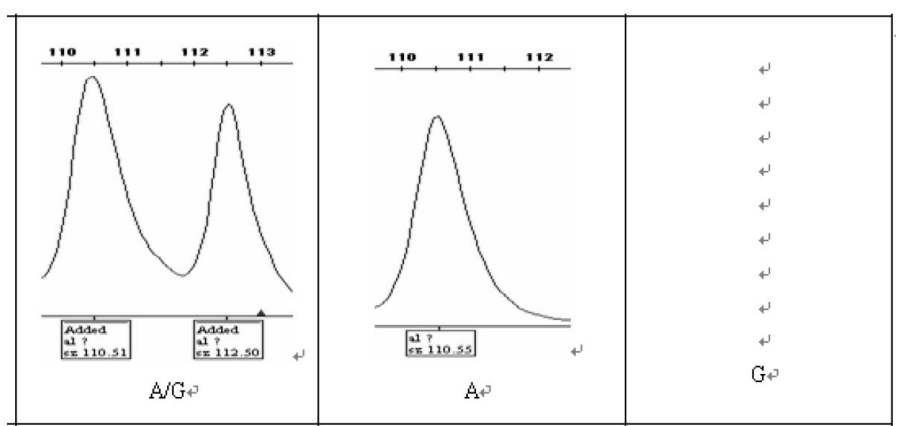

Figure 4. Genotype result of PGC-1 $\alpha$ A948G. sz = represents size.

Table 3. Allelic frequencies of the four polymorphhic sites in two chicken breeds.

\begin{tabular}{|c|c|c|c|c|c|c|c|c|}
\hline \multirow[t]{2}{*}{ Breed $^{1}(\mathrm{~N})$} & \multicolumn{2}{|c|}{171} & \multicolumn{2}{|c|}{384} & \multicolumn{2}{|c|}{646} & \multicolumn{2}{|c|}{948} \\
\hline & $\mathrm{C}$ & $\mathrm{T}$ & $\mathrm{C}$ & $\mathrm{T}$ & G & A & G & A \\
\hline RW (200) & 1.00 & 0 & 1.00 & 0 & 0.71 & 0.29 & 0.90 & 0.10 \\
\hline QY (200) & 0.87 & 0.13 & 0.96 & 0.04 & 0.86 & 0.14 & 0.91 & 0.09 \\
\hline
\end{tabular}

${ }^{1} \mathrm{RW}$ and QY represent Recessive White chicken breeds and Qingyuan partridge chicken, respectively.

\section{Haplotypes and their frequencies}

Haplotypes constructed based on four SNPs and their frequencies in the two breeds are shown in Table 4. Seven haplotypes were indentified in 400 chickens, in which the two most abundant ones, designated H1 (CCAA) and H3 (CCGA), accounted for about $95 \%$ of the genetic information. Haplotype H3 was predominant in both the Recessive White breed and Qingyuan partridge breed.

Table 4. Haplotypes constructed with 4 single nucleotide polymorphisms (SNP) and frequencies in the two chicken breeds.

\begin{tabular}{|c|c|c|c|c|c|c|}
\hline \multirow[t]{2}{*}{ Haplotype } & \multicolumn{4}{|c|}{ Site } & \multicolumn{2}{|c|}{ Breed $^{1}$} \\
\hline & 171 & 384 & 646 & 948 & QY & RW \\
\hline h1 & $\mathrm{C}$ & $\mathrm{C}$ & A & A & 0.099 & 0.328 \\
\hline h2 & C & $\mathrm{C}$ & A & G & 0.025 & - \\
\hline h3 & C & $\mathrm{C}$ & G & A & 0.683 & 0.602 \\
\hline h4 & C & $\mathrm{C}$ & G & G & 0.054 & 0.070 \\
\hline h5 & $\mathrm{T}$ & C & A & $\mathrm{G}$ & 0.020 & - \\
\hline h6 & $\mathrm{T}$ & $\mathrm{C}$ & G & A & 0.084 & - \\
\hline h7 & C & $\mathrm{T}$ & G & A & 0.035 & - \\
\hline
\end{tabular}

${ }^{1} \mathrm{QY}$ and RW represent Qingyuan partridge chicken and Recessive White chicken breeds, respectively. 


\section{Marker-trait association analysis}

Statistical analysis was applied to test the significance of the difference in breed effect, genotype effect and the interaction between the genotype effect and the breed effect between different genotypes of the two loci, respectively. The breed effect and the interaction between the genotype effect and the breed effect were not significant. There was a significant genotypic effect only in the G646A polymorphic locus, and therefore, we further analyzed the genotypic effect of G646A site with the combination of the two breeds (Table 5 ). With regard to the myofiber type trait, individuals with the AA genotype had a significantly higher slow-twitch myofiber ratio than did those with the GG and GA genotypes (P $<0.05$ ), and GA genotype birds also had significantly higher slow-twitch myofiber ratio compared to GG genotype birds $(\mathrm{P}<0.05)$. Meanwhile, AA and GA genotype birds had significantly lower white fast-twitch myofiber ratio than did GG genotype birds $(\mathrm{P}<0.05)$, while AA genotype birds also had a little lower white fast-twitch myofiber ratio than did GA genotype birds, but the difference was not significant. The associations between genotypes and diameter and density of muscle fibers and IMF content were also significant. AA and GA genotype birds had significantly lower muscle fiber diameter and muscle fiber density compared to GG genotype birds $(\mathrm{P}<0.05)$. The IMF content of individuals with the AA genotype was significantly higher than that of individuals with GG and GA genotype $(\mathrm{P}<$ $0.05)$. However, there was no significant association between genotypes and red fast-twitch myofiber ratio, shear forces and water loss rate.

Table 5. Association of G646A genotypes with myofiber types and other meat quality traits in chicken breeds.

\begin{tabular}{lrrr}
\hline Traits & \multicolumn{1}{c}{ GG } & GA & AA \\
\hline Slow-twitch myofibers ratio (\%) & $40.3 \pm 3.05^{\mathrm{a}}$ & $44.9 \pm 2.12^{\mathrm{b}}$ & $49.8 \pm 3.13^{\mathrm{c}}$ \\
Red fast-twitch myofibers ratio (\%) & $13.55 \pm 2.10$ & $21.25 \pm 3.25$ & $15.3 \pm 2.24$ \\
White fast-twitch myofibers ratio (\%) & $48.05 \pm 1.25^{\mathrm{a}}$ & $39.95 \pm 1.32^{\mathrm{b}}$ & $38.15 \pm 1.57^{\mathrm{b}}$ \\
Muscle fiber diameter (um) & $53.44 \pm 3.25^{\mathrm{a}}$ & $46.13 \pm 2.32^{\mathrm{b}}$ & $47.55 \pm 3.48^{\mathrm{b}}$ \\
Muscle fiber density & $415.25 \pm 3.45^{\mathrm{a}}$ & $316.15 \pm 2.56^{\mathrm{b}}$ & $302.13 \pm 4.11^{\mathrm{b}}$ \\
Shear forces (kg) & $2.369 \pm 0.048$ & $2.359 \pm 0.091$ & $2.393 \pm 0.210$ \\
Water loss rate (\%) & $0.328 \pm 0.013$ & $0.310 \pm 0.006$ & $0.300 \pm 0.005$ \\
IMF (\%) & $1.038 \pm 0.049^{\mathrm{a}}$ & $1.106 \pm 0.092^{\mathrm{a}}$ & $1.375 \pm 0.212^{\mathrm{b}}$ \\
\hline
\end{tabular}

a,b Means with the different superscripts within the same row differs significantly $(\mathrm{P}<0.05)$.

According to the results of the PHASE 2.0 software, seven haplotypes (H1: CCAA, H2: CCAG, H3: CCGA, H4: CCGG, H5: TCAG; H6: TCGA, H7: CTGA) were constructed. Nine diplotypes with frequencies higher than $2 \%(4$ of $\mathrm{H} 1 \mathrm{H} 1,22$ of $\mathrm{H} 1 \mathrm{H} 3,6$ of H1H6, 6 of $\mathrm{H} 2 \mathrm{H} 3,94$ of $\mathrm{H} 3 \mathrm{H} 3,18$ of $\mathrm{H} 3 \mathrm{H} 4,6$ of $\mathrm{H} 3 \mathrm{H} 5,26$ of $\mathrm{H} 3 \mathrm{H} 6$ and 10 of $\mathrm{H} 3 \mathrm{H} 7$ ) were observed in Qingyuan partridge chickens, and five diplotypes $(10$ of $\mathrm{H} 1 \mathrm{H} 1,92$ of $\mathrm{H} 1 \mathrm{H} 3$, 58 of $\mathrm{H} 3 \mathrm{H} 3,22$ of $\mathrm{H} 3 \mathrm{H} 4$, and 4 of $\mathrm{H} 1 \mathrm{H} 4)$ in Recessive White chickens, so a total of 400 individuals with ten diplotypes (14 of H1H1, 114 of H1H3, 6 of H1H6, 6 of H2H3, 152 of $\mathrm{H} 3 \mathrm{H} 3,40$ of $\mathrm{H} 3 \mathrm{H} 4,6$ of $\mathrm{H} 3 \mathrm{H} 5,26$ of $\mathrm{H} 3 \mathrm{H} 6,10$ of $\mathrm{H} 3 \mathrm{H} 7$ and 4 of $\mathrm{H} 1 \mathrm{H} 4)$ were used in the association analysis, and significant association $(\mathrm{P}<0.05)$ of the haplotypes with myofiber types was observed (Table 6). Among the ten diplotypes, H1H1 had a significantly higher $(\mathrm{P}<0.05)$ mean value of slow-twitch myofiber ratio compared to the other diplotypes, while $\mathrm{H} 3 \mathrm{H} 4$ had a significantly higher $(\mathrm{P}<0.05)$ mean value of white fast-twitch myofiber ratio compared to the other diplotypes. 
Table 6. Least square means \pm standard errors of myofiber types according to haplotype combinations ${ }^{1}$.

\begin{tabular}{lccc}
\hline Trait & Slow-twitch myofibers ratio (\%) & red fast-twitch myofibers ratio (\%) & white fast-twitch myofibers ratio (\%) \\
\hline H1H1 (14) & $48.2 \pm 3.2^{\mathrm{a}}$ & $14.5 \pm 1.4$ & $39.3 \pm 3.1^{\mathrm{a}}$ \\
H1H3 (114) & $43.5 \pm 2 .^{\mathrm{b}}$ & $15.3 \pm 1.9$ & $40.2 \pm 2.4^{\mathrm{a}}$ \\
H1H6 (6) & $44.5 \pm 2.6^{\mathrm{b}}$ & $14.8 \pm 1.5$ & $40.7 \pm 2.5^{\mathrm{a}}$ \\
H2H3 (6) & $44.2 \pm 2 .^{\mathrm{b}}$ & $14.5 \pm 1.7$ & $41.3 \pm 2.2^{\mathrm{a}}$ \\
H3H3 (152) & $42.5 \pm 2.7^{\mathrm{b}}$ & $15.3 \pm 2.2$ & $42.2 \pm 2.5^{\mathrm{a}}$ \\
H3H4 (40) & $41.2 \pm 2.2^{\mathrm{b}}$ & $14.3 \pm 1.6$ & $44.5 \pm 2.1^{\mathrm{b}}$ \\
H3H5 (6) & $44.8 \pm 2.4^{\mathrm{b}}$ & $13.6 \pm 1.9$ & $41.6 \pm 2.5^{\mathrm{a}}$ \\
H3H6 (26) & $43.9 \pm 2.5^{\mathrm{b}}$ & $14.1 \pm 1.8$ & $42.0 \pm 2.1^{\mathrm{a}}$ \\
H3H7 (10) & $43.8 \pm 2.1^{\mathrm{b}}$ & $14.6 \pm 1.5$ & $41.6 \pm 2.3^{\mathrm{a}}$ \\
H1H4 (4) & $44.9 \pm 2.6^{\mathrm{b}}$ & $14.8 \pm 1.9$ & $40.3 \pm 2.3^{\mathrm{a}}$
\end{tabular}

a,b Means with the different superscripts within the same column differs significantly $(\mathrm{P}<0.05) .{ }^{1}$ Only the haplotype combinations for which the observed number was no less than 4 were listed. ${ }^{2}$ The number in parentheses is the observed number for a particular haplotype combination.

\section{DISCUSSION}

In the present study, we describe the development of a new mutation detection method based on PCR-LDR, which is highly sensitive and quantitative. A distinguishing feature of PCR-LDR is that misligations do not undergo subsequent amplification, therefore reducing the chance of false positive reactions. Any low-level polymerase errors remain unselected, and thus contribute only minimal background noise. It has been used in the detection of some viruses, oncogenes and tumor-suppressor genes (Khanna et al., 1999; Rondini et al., 2008).

Recently, myofiber-type composition of skeletal muscle has attracted great attention both in human health and animal production, owing to its close association with insulin sensitivity in mammals (Hickey et al., 1995; Korach-André et al., 2005) and its significance for lean-mass deposition and meat quality in meat-producing animals (Maltin et al., 2003), respectively. Adult skeletal muscle displays plasticity that allows the conversion of different fiber types in response to chronic change in contractile demands (Hood, 2001; Schiaffino and Reggiani, 2011). Recent work has implicated the transcriptional coactivator PGC-1a in muscle fiber type switching and determination (Lin et al., 2002; Liang et al., 2009).

The genetic effect of PGC- $1 \alpha$ gene on myofiber type determination has not been studied to date. Wu et al. (2006) reported that a $\mathrm{G}$ to A polymorphism at position 646 of the open reading frame in the chicken PGC-1 $\alpha$ gene was significantly related to abdominal fat weight, and had no effects on growth traits, so this SNP could be a molecular marker for the selection of abdominal fat. An et al. (2008) further studied the genetic effect of this SNP on meat quality in White Plymouth Rock and found that birds with the AG genotype had better meat quality. In the present study, PCR/LDR method was used to genotype single nucleotide polymorphisms of the coding region of the PGC- $1 \alpha$ gene in an important Chinese indigenous chicken breed with better meat quality, Qingyuan partridge chicken, and one commercial breed, Recessive White chicken. Four SNPs (C171T, C384T, G646A, and A948G) were detected, and the genotyping results were in concordance with direct DNA sequencing, indicating the accuracy of the PCR-LDR method. Although the meat quality traits between the two chicken breeds were significantly different, the allele frequencies of the two sites in both breeds were close. The frequencies of $\mathrm{C} 171$ and $\mathrm{C} 384$ allele were 1.0 in Recessive White chickens, and the G allele was the most frequent in both breeds, which agreed with that in White Plymouth Rock (Wu 
et al., 2006). Only G646A genotypes of the PGC-1 $\alpha$ gene showed a significant association with myofiber types and other meat quality traits when further association studies were carried out at each polymorphism. Moreover, the breed effect and the interaction effect between breeds and genotypes were not significant, and therefore, it was concluded that there may be a relationship between this SNP site and meat quality traits in chickens. Meanwhile, breeders can reduce abdominal fat significantly by selecting AA birds without affecting the continued improvement of growth rate (Wu et al., 2006).

Haplotype analysis is very important in the mapping of complex-disease genes because of the abundance of SNPs and the limited power of conventional single-site analyses (Cardon and Abecasis, 2003; Lin, 2004). In this study, haplotypes were constructed with the 4 SNPs, and the association of haplotype combinations with myofiber type and other meat quality traits was analyzed. The $\mathrm{H} 1 \mathrm{H} 1$ diplotype was found to be associated with a high ratio of slow-twitch myofiber compared to other diplotypes $(\mathrm{H} 1 \mathrm{H} 3, \mathrm{H} 1 \mathrm{H} 6, \mathrm{H} 2 \mathrm{H} 3, \mathrm{H} 3 \mathrm{H} 3, \mathrm{H} 3 \mathrm{H} 4$, $\mathrm{H} 3 \mathrm{H} 5, \mathrm{H} 3 \mathrm{H} 6, \mathrm{H} 3 \mathrm{H} 7$, and $\mathrm{H} 1 \mathrm{H} 4)$, while $\mathrm{H} 3 \mathrm{H} 4$ had a significantly higher ratio of white fasttwitch myofiber than did other diplotypes. The difference between H1 (CCAA), H3 (CCGA) and $\mathrm{H} 4$ (CCGG) haplotypes existed at the G646A and A948G sites, and therefore, these two sites may have a greater genetic effect, and H1 may be the most advantageous haplotype for myofiber types because of nucleotide substitution interaction (Putt et al., 2004).

The results obtained in current study showed that polymorphisms of the PGC- $1 \alpha$ gene and their haplotypes are associated with chicken myofiber type as well as other meat quality traits, where the H1H1 diplotype could be a potential marker for myofiber type trait.

\section{ACKNOWLEDGMENTS}

Research supported by the National Natural Science Foundation of China (\#31301967), the Earmarked Fund for Modern Agro-Industry Technology Research System, National High Technology Research and Development Program “863” (\#2011AA100301,\#2011AA100305), Natural Science Foundation of Jiangsu Province (\#BK2012268), and Introduction Project for Advanced International Scientific Technology of Agriculture (\#2011-Z65).

\section{REFERENCES}

An JY, Chen L, Hou ZC and Wu GQ (2008). The statistical analysis on the effect of the SNP in PGC-1 $\alpha$ on meat quality in White Plymouth Rock. Acta Vet. Zootechnica Sin. 39: 715-720.

Barany F and Gelfand DH (1991). Cloning, overexpression and nucleotide sequence of a thermostable DNA ligaseencoding gene. Gene 109: 1-11.

Berchtold MW, Brinkmeier H and Muntener M (2000). Calcium ion in skeletal muscle: its crucial role for muscle function, plasticity, and disease. Physiol. Rev. 80: 1215-1265.

Booth FW and Thomason DB (1991). Molecular and cellular adaptation of muscle in response to exercise: perspectives of various models. Physiol. Rev. 71: 541-585.

Cardon LR and Abecasis GR (2003). Using haplotype blocks to map human complex trait loci. Trends Genet. 19: 135-140.

Chen GH, Hou SS, Wu XS, Wang KH, et al. (2000). Comparison between inosinic acid content of muscle in Chinese native chickens. Acta Vet. Zootechnica Sin. 31: 211-215.

Dutka TL, Mollica JP, Posterino GS and Lamb GD (2011). Modulation of contractile apparatus $\mathrm{Ca}^{2+}$ sensitivity and disruption of excitation-contraction coupling by S-nitrosoglutathione in rat muscle fibres. J. Physiol. 589: 2181-2196.

Hickey MS, Carey JO, Azevedo JL, Houmard JA, et al. (1995). Skeletal muscle fiber composition is related to adiposity and in vitro glucose transport rate in humans. Am. J. Physiol. 268: E453-E457.

Hollingworth S, Kim MM and Baylor SM (2012). Measurement and simulation of myoplasmic calcium transients in 
mouse slow-twitch muscle fibres. J. Physiol. 590: 575-594.

Hood DA (2001). Contractile activity-induced mitochondrial biogenesis in skeletal muscle. J. Appl. Physiol. 90: $1137-$ 1157.

Hoogenraad TU, Jennekens FG and Tan KE (1979). Histochemical fibre types in human extraocular muscles, an investigation of inferior oblique muscle. Acta Neuropathol. 45: 73-78.

Jiang XS and Groen AF (2000). Chicken breeding with local breeds in China. Asian-Australasian J. Anim. Sci. 13: 14821498.

Karlsson AH, Klont RE and Fernandez X (1999). Skeletal muscle fibres as factors for pork quality. Livestock Prod. Sci. 60: 255-269.

Khanna M, Park P, Zirvi M, Cao W, et al. (1999). Multiplex PCR/LDR for detection of K-ras mutations in primary colon tumors. Oncogene 18: 27-38.

Korach-André M, Gounarides J, Deacon R, Beil M, et al. (2005). Age and muscle-type modulated role of intramyocellular lipids in the progression of insulin resistance in nondiabetic Zucker rats. Metabolism 54: 522-528.

Liang H, Balas B, Tantiwong P, Dube J, et al. (2009). Whole body overexpression of PGC-1 $\alpha$ has opposite effects on hepatic and muscle insulin sensitivity. Am. J. Physiol. Endocrinol. Metab. 296: E945-E954.

Lin DY (2004). Haplotype-based association analysis in cohort studies of unrelated individuals. Genet. Epidemiol. 26: 255-264.

Lin J, Wu H, Tarr PT, Zhang CY, et al. (2002). Transcriptional co-activator PGC-1 $\alpha$ drives the formation of slow-twitch muscle fibres. Nature 418: 797-801.

Maltin C, Balcerzak D, Tilley R and Delday M (2003). Determinants of meat quality: tenderness. Proc. Nutr. Soc. 62: 337-347.

Michael LF, Wu Z, Cheatham RB, Puigserver P, et al. (2001). Restoration of insulin-sensitive glucose transporter (GLUT4) gene expression in muscle cells by the transcriptional coactivator PGC-1. Proc. Natl. Acad. Sci. U. S. A. 98: 3820-3825.

Pette D and Staron RS (2001). Transitions of muscle fiber phenotypic profiles. Histochem. Cell Biol. 115: 359-372.

Puigserver P, Wu Z, Park CW, Graves R, et al. (1998). A cold-inducible coactivator of nuclear receptors linked to adaptive thermogenesis. Cell 92: 829-839.

Putt W, Palmen J, Nicaud V, Tregouet DA, et al. (2004). Variation in USF1 shows haplotype effects, gene: gene and gene :environment associations with glucose and lipid parameters in the European Atherosclerosis Research Study II. Hum. Mol. Genet. 13: 1587-1597.

Rondini S, Pingle MR, Das S, Tesh R, et al. (2008). Development of multiplex PCR-ligase detection reaction assay for detection of West Nile virus. J. Clin. Microbiol. 46: 2269-2279.

Schiaffino S and Reggiani C (2011). Fiber types in mammalian skeletal muscles. Physiol. Rev. 91: 1447-1531.

Stephens M, Smith NJ and Donnelly P (2001). A new statistical method for haplotype reconstruction from population data. Am. J. Hum. Genet. 68: 978-989.

Vega RB, Huss JM and Kelly DP (2000). The coactivator PGC-1 cooperates with peroxisome proliferator-activated receptor alpha in transcriptional control of nuclear genes encoding mitochondrial fatty acid oxidation enzymes. Mol. Cell Biol. 20: 1868-1876.

Walter I and Seebacher F (2007). Molecular mechanisms underlying the development of endothermy in birds (Gallus gallus): a new role of PGC-1 $\alpha$ ? Am. J. Physiol. Regul. Integr. Comp Physiol. 293: R2315-R2322.

Wegner J, Albrecht E, Fiedler I, Teuscher F, et al. (2000). Growth- and breed-related changes of muscle fiber characteristics in cattle. J. Anim. Sci. 78: 1485-1496.

Wu GQ, Deng XM, Li JY, Li N, et al. (2006). A potential molecular marker for selection against abdominal fatness in chickens. Poult. Sci. 85: 1896-1899.

Wu Z, Puigserver P, Andersson U, Zhang C, et al. (1999). Mechanisms controlling mitochondrial biogenesis and respiration through the thermogenic coactivator PGC-1. Cell 98: 115-124.

Yuan Y, Liu YG, Shi XE and Yang GS (2010). Signaling pathways in skeletal muscle fiber-type transition. Chin. J. Biochem. Mol. Biol. 26: 796-801. 